\begin{tabular}{|c|c|c|}
\hline Case Reports in & \multicolumn{2}{|c|}{ Case Rep Gastroenterol 2016;10:302-307 } \\
\hline Gastroenterology & $\begin{array}{l}\text { DOI: } 10.1159 / 000446764 \\
\text { Published online: June 14, } 2016\end{array}$ & $\begin{array}{l}\text { ( ) } 2016 \text { The Author(s) } \\
\text { Published by S. Karger AG, Basel } \\
\text { www.karger.com/crg }\end{array}$ \\
\hline & $\begin{array}{l}\text { This article is licensed under } \\
\text { International License (CC BY-N } \\
\text { Usage and distribution for comm }\end{array}$ & $\begin{array}{l}\text { nons Attribution-NonCommercial } 4.0 \\
\text { ger.com/Services/OpenAccessLicense). } \\
\text { uires written permission. }\end{array}$ \\
\hline
\end{tabular}

\title{
Laparoscopic and Endoscopic Cooperative Surgery for Plexiform Angiomyxoid Myofibroblastic Tumor
}

\author{
Yoshio Nagahisa Tadashi Itou Chika Okita Tatsuya Yamakawa \\ Kai Chen Yusuke Kouda Kazuki Hashida \\ Department of Surgery, Kurashiki Central Hospital, Kurashiki City, Japan
}

\section{Keywords}

Laparoscopic and endoscopic cooperative surgery · Plexiform angiomyxoid myofibroblastic tumor - Gastric submucosal tumors

\begin{abstract}
Plexiform angiomyxoid myofibroblastic tumor (PAMT) is a recently described distinctive gastric mesenchymal entity with a peculiar plexiform pattern, bland spindle cells and a myxoid stroma rich in arborizing blood vessels. In this study, we report a new case of this rare gastric tumor resected by laparoscopic and endoscopic cooperative surgery (LECS). A 39-year-old Japanese man was admitted with a gastric mass. Gastroscopy showed an elevated mass in the anterior wall of the gastric antrum. Endoscopic ultrasound examination revealed a focal hypoechoic lesion protruding into the lumen. A partial gastrectomy by LECS was performed, and the patient made an uneventful recovery and remains well 9 months later. The tumor in this case depicted all the typical histopathologic and immunochemical features of gastric PAMT (c-kit negative and smooth muscle actin-positive). Especially, it was characterized by multiple nodules protruding outward within the serosa. Therefore, it is important that the resection line is determined on the serosa to ensure the complete resection of these nodules together.

(C) 2016 The Author(s)

Published by S. Karger AG, Basel
\end{abstract}




\section{Background}

Laparoscopic gastric resection is widely used for gastric submucosal tumors (SMTs). However, it is difficult to determine an appropriate resection line using only the laparoscopic approach. For more appropriate resection, laparoscopic and endoscopic cooperative surgery (LECS) was developed by Hiki et al. [1]. On the other hand, gastric plexiform angiomyxoid myofibroblastic tumor (PAMT) has recently emerged as a new entity among gastrointestinal mesenchymal tumors which was first described by Takahashi et al. [2] in 2007. PAMT is a very rare mesenchymal tumor and develops like SMTs. This is a rare tumor with equal gender distribution and occurs primarily in adults with a wide age range of 7-83 years [3,4]. Due to its rarity, the true biological potential of PAMT remains unknown. However, the bland nuclear features, low proliferative index and absence of necrosis, vascular invasion, recurrence and metastasis in all cases of PAMT reported to date justify its characterization as a benign tumor. Sing et al. [5] suggested that vascular invasion and extragastric extension of the tumor were not typically observed in PAMT. Currently, distal or partial gastrectomy remains the treatment of choice. To our knowledge, our case is the first reported case of PAMT resected by LECS.

\section{Case Report}

A 39-year-old male patient visited our hospital because of epigastric pain. In an upper gastrointestinal endoscopy examination, a submucosal tumor was found in the antrum with partial ulceration on the surface. Gastroscopy revealed a $3.5 \times 3.0 \mathrm{~cm}$ sessile polypoid mass with a smooth surface in the anterior wall of the gastric antrum with a recessed area. This area looked like mucosal ulceration covered with gastric mucosa. Endoscopic ultrasound examination revealed a focal hypoechoic lesion protruding into the lumen. We considered that this tumor was located in the muscle layer (fig. 1). There were no malignant cells in biopsy.

The CT scan showed a heterogeneous tumor in the gastric antrum, which was drastically enhanced with contrast medium, and consisted of a number of highly stained small nodules around the tumor rim (fig. 2). There was no evidence of metastasis.

Radiological imaging suggested differential diagnoses of angioma and solitary fibromyxoma because of the hypervascular nature of the tumor. However, because the tumor did not protrude into the lumen of the stomach, these diagnoses were unlikely. Furthermore, the imaging findings ruled out the possibility of gastrointestinal stromal tumor.

\section{Surgery}

To facilitate appropriate resection without injuring the pylorus, we choose LECS. LECS combines laparoscopic gastric resection with endoscopic imaging for tumor location and determining an appropriate resection line. We performed 4-port surgery (fig. 3a). Aggregations of small polypoid nodules, red-colored and angiomatous, were characteristically seen on the serous membrane surface, and appeared like a metastatic lymph node nodule (fig. 3b).

First, we located the tumor and cut the surrounding mucosa of the lesion by endoscope. We perforated the gastric wall at the distal side of the tumor using needle knife without in- 
juring the pylorus. Next, the seromuscular layer was dissected laparoscopically with an ultrasonically activated device tracing the mucosal line cut. A partial gastrectomy by LECS revealed the tumor at the antrum of the greater curvature side of the stomach, and the incision line was closed on suturing by layer-to-layer anastomosis.

The resected tumor, $3.5 \mathrm{~cm}$ in size, was covered with normal mucosa. The tumor was composed of bland spindle cells which were separated by abundant myxomatous stroma and showed plexiform growth in the entire stomach wall (fig. 4). The tumor cells were negative for CD117 (c-kit), CD34 and S-100 protein, but diffusely positive for smooth muscle actin consistent with predominant myofibroblastic differentiation (fig. 5). The tumor was especially characterized by multiple nodules protruding outward from within the serosa, and we diagnosed the patient with PAMT.

The patient received supportive care without any specific medication during hospitalization and had no recurrence or metastasis during follow-up for 9 months after the surgery.

\section{Discussion}

PAMT is a rare mesenchymal tumor of the stomach, which consists of spindle cells with myofibroblastic characteristics. PAMT is also called plexiform angiomyxoma, angiomyxoid tumor or myxofibroma. Miettinen et al. [6] estimated that the frequency of PAMT is less than $1 / 150$ that of gastrointestinal stromal tumor, but only 28 cases of PAMT have been reported, including the present case [7]. The prevalence of PAMT does not vary by sex (M:F = 1:1) and it can develop at any age (range: 7-83 years).

There are few reports describing the CT findings for PAMT $[2,7]$. They reported that CT findings of tumor location in the gastric antrum, a heterogeneous internal enhancement effect, and small nodules with a strong enhancement in the rim could be used for radiologic diagnosis of PAMT. In our case, all three CT findings were evident.

PAMT is considered a benign tumor. However, due to its rarity, the true biological potential of PAMT remains unknown. So, complete resection when functional preservation is possible is appropriate. On the other hand, the optimal procedure for PAMT remains unreported. Currently, distal or partial gastrectomy remains the treatment of choice. LECS is the best procedure for complete resection while preserving the pylorus because of the gastric antrum of predilection for PAMT. To our knowledge, our case is the first reported case of PAMT resected by LECS.

\section{Conclusion}

PAMT is a very rare gastric tumor of mesenchymal origin. When a myxoid spindle cell lesion is observed in endoscopic biopsy or when there are characteristic CT findings, PAMT should be included in the differential diagnosis. Our case demonstrated that LECS is a useful procedure for the resection of PAMT.

\section{Statement of Ethics}

Case details and images were used with the patient's informed consent. 
Nagahisa et al.: Laparoscopic and Endoscopic Cooperative Surgery for Plexiform Angiomyxoid Myofibroblastic Tumor

\section{Disclosure Statement}

The authors declare no conflicts of interest.

\section{References}

1 Hiki N, Yamamoto Y, Fukunaga T, Yamaguchi T, Nunobe S, Tokunaga M, Miki A, Ohyama S, Seto Y: Laparoscopic and endoscopic cooperative surgery for gastrointestinal stromal tumor dissection. Surg Endosc 2008;22:1729-1735.

2 Takahashi Y, Shimizu S, Ishida T, Aita K, Toida S, Fukusato T, Mori S: Plexiform angiomyxoid myofibroblastic tumor of the stomach. Am J Surg Pathol 2007;31:724-728.

3 Wang LM, Chetty R: Selected unusual tumors of the stomach: a review. Int J Surg Pathol 2012;20:5-14.

4 Duckworth LV, Gonzalez RS, Martelli M, Liu C, Coffin CM, Reith J: Plexiform fibromyxoma: report of two pediatric cases, including the first example in the esophagus. Pediatr Dev Pathol 2013, Epub ahead of print.

$5 \quad$ Sing Y, Subayan S, Mqadi B, Ramdial PK, Reddy J, Moodley MS, Bux S: Gastric plexiform angiomyxoid myofibroblastic tumor. Pathol Int 2010;60:621-625.

6 Miettinen M, Makhlouf HR, Sobin LH, Lasota J: Plexiform fibromyxoma. Am J Surg Pathol 2009;33:16241632.

7 Ikemura M, Maeda E, Hatao F, Aikou S, Seto Y, Fukayama M: Plexiform angiomyxoid myofibroblastic tumor (PAMT) of the stomach. A case report focusing on its characteristic growth pattern. Int J Clin Exp Pathol 2014;7:685-689.
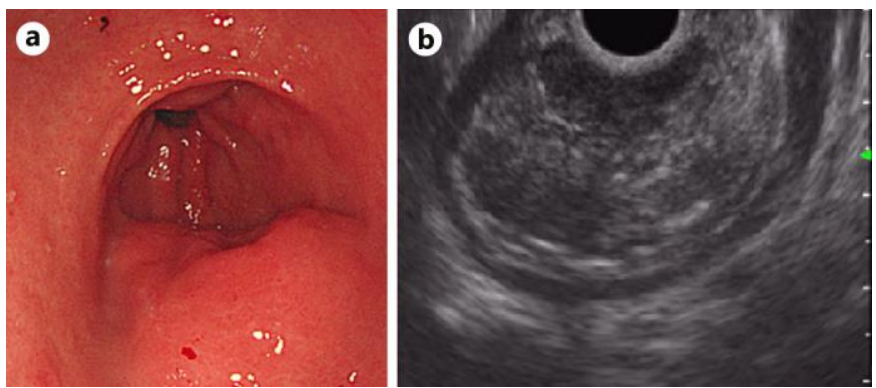

Fig. 1. An upper gastrointestinal endoscopy and ultrasound examination. a There are SMTs on the antrum with focal ulceration of the mucosa. $\mathbf{b}$ Focal hypoechoic lesion protruding into the lumen. 


\section{Case Reports in \\ Gastroenterology}

\begin{tabular}{l|l}
\hline Case Rep Gastroenterol 2016;10:302-307 \\
\hline $10.1159 / 000446764$ & $\begin{array}{l}\text { C 2016 The Author(s). Published by S. Karger AG, Basel } \\
\text { www.karger.com/crg }\end{array}$ \\
\hline
\end{tabular}

Nagahisa et al.: Laparoscopic and Endoscopic Cooperative Surgery for Plexiform Angiomyxoid Myofibroblastic Tumor

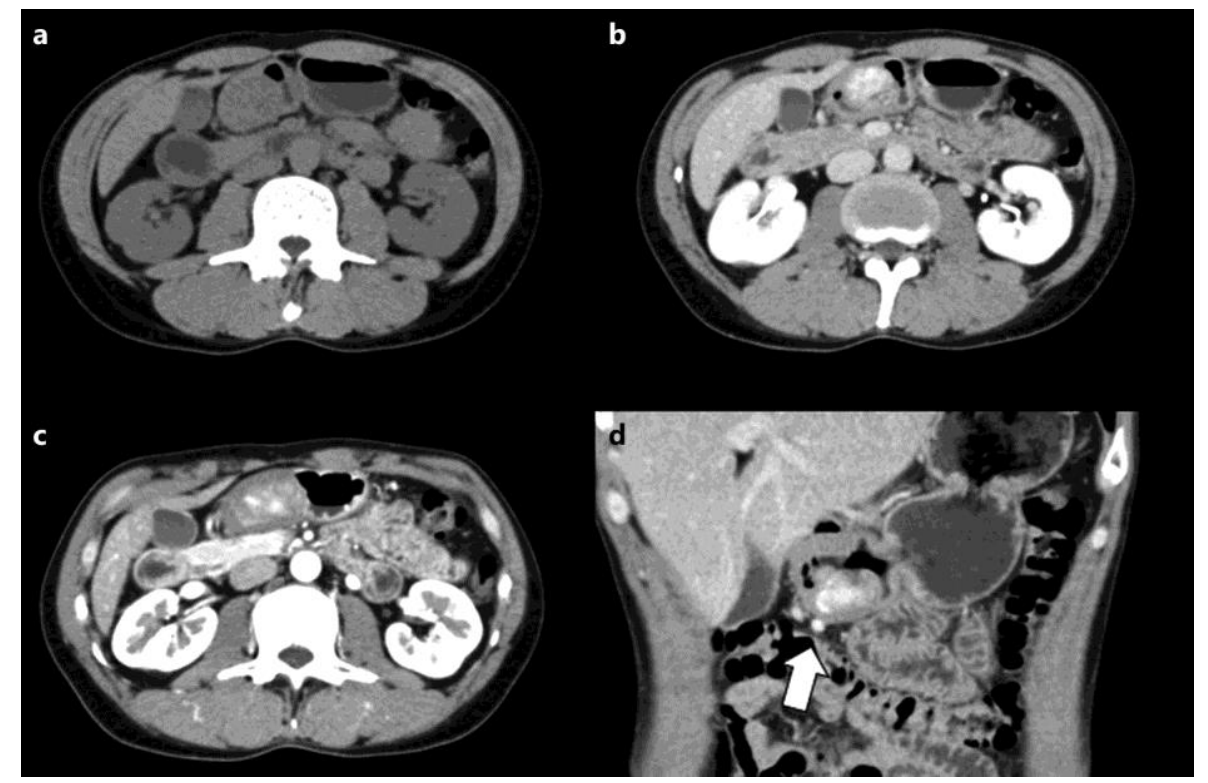

Fig. 2. CT scan of the tumor. a Unenhanced CT image shows a inhomogeneous tumor mass in the antrum of the stomach. b, c Contrast-enhanced CT image revealed a tumor mass with an inhomogeneous, prominent enhancement in the late phase of contrast imaging. d Arrow indicates the enhanced small nodules in the serosa.
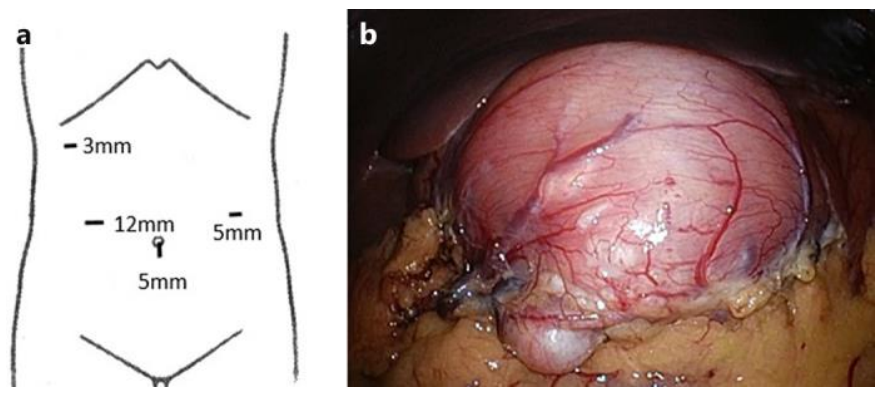

Fig. 3. Surgical findings. a Port site. b Small polypoid nodules on serosa was connected to the main tumor. 

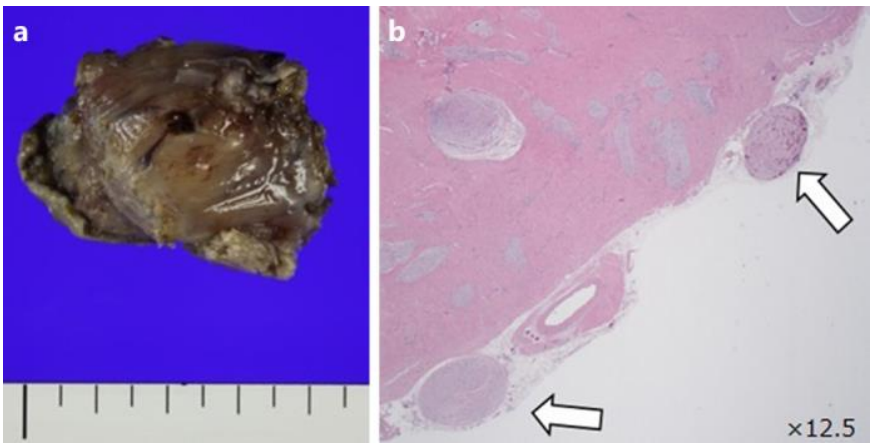

Fig. 4. Gross and histological examination. a $2.3 \times 2.8 \times 3.5-\mathrm{cm}$ lobulated tumor showed a mixture of whitefibrous, myxomatous small polypoid nodules on serosa which were connected to the main tumor. $\mathbf{b}$ The tumor contains spindle-shaped bland tumor cells in a fibromyxoid stroma. HE. ×12.5.
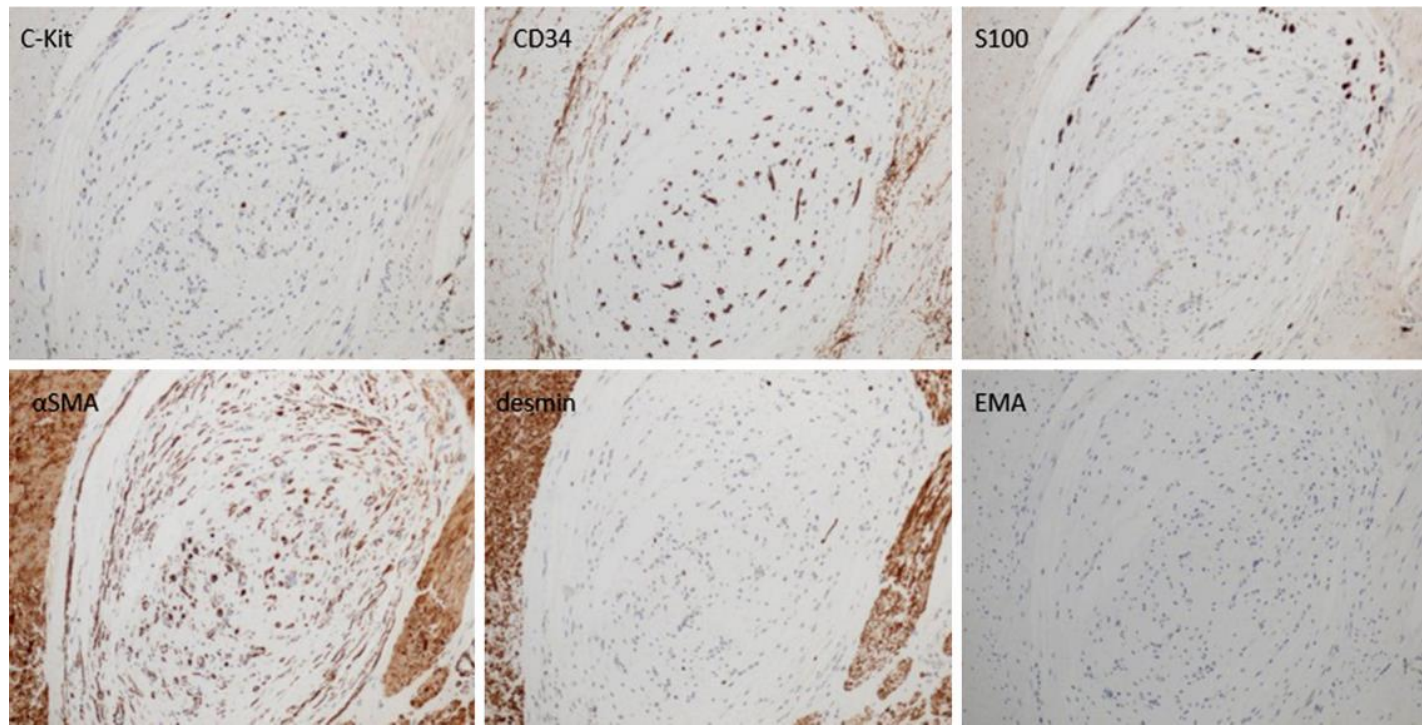

Fig. 5. Immunohistochemistry $(\times 200)$. The results of other markers were c-kit $(-)$, CD34(-), S-100 protein(), desmin(-) and EMA(-) but diffusely positive for smooth muscle actin consistent. 